\title{
HUBUNGAN POSISI KERJA DENGAN KELUHAN MUSKULOSKELETAL PADA KARYAWAN- KARYAWATI SWALAYAN DIAMOND MEDAN JOHOR
}

\author{
The Relationship of Work Position With Musculoskeletal Complaints \\ in Employees in Diamond Shop Medan Johor
}

\author{
Nanda Novziransyah ${ }^{1}$, Deny Syahputra ${ }^{2}$, Erika Depianti ${ }^{3}$, \\ Muhammad Ramadhan Mukhtar ${ }^{4}$ \\ ${ }^{1}$ Dosen Tetap Fakultas Kedokteran Universitas Islam Sumatera Utara-Medan \\ 2,3,4 Mahasiswa Fakultas Kedokteran Universitas Islam Sumatera Utara-Medan \\ E-mail : ndanovzi@yahoo.com
}

\begin{abstract}
Abstrak
Ergonomi merupakan penerapan ilmu-ilmu biologis tentang manusia bersama-sama dengan ilmu-ilmu teknik dan teknologi untuk mencapai penyesuaian. Keluhan muskuloskeletal adalah keluhan sakit, nyeri, pegal-pegal dan lainnya pada sistem otot (muskuloskeletal) seperti tendon, pembuluh darah, sendi, tulang, syaraf dan lainnya yang disebabkan oleh aktivitas kerja. Suatu survey yang dilakukan oleh Simon Fraser University and the United Food and Commercial Workers mengidikasikan 30\% pekerja kasar menderita MSD. Tujuan dari penelitian ini adalah untuk mengetahui Hubungan berbagai posisi kerja dengan keluhan muskulosekeletal pada karyawan-karyawati swalayan Diamond Medan Johor. Manfaat penelitian ini diharapkan dapat disebarluaskan di media massa tentang hubungan posisi kerja dengan keluhan muskuloskeletal sehingga dapat bermanfaat bagi karyawan-karyawati lainnya. Desain penelitian ini adalah menggunakan metode penelitian analitik pendekatan cross sectional dengan besar sampel 60 orang. Penelitian ini dilakukan pada bulan April sampai Mei 2018 dan alat pengumpulan data yang di pakai adalah dengan menggunakan lembaran kesioner. Hasil penelitian ini menunjukkan bahwa keluhan muskuloskeletal berupa nyeri terbanyak yaitu pada posisi mengangkat (Staf Area) 31 orang (50.6\%), dimana 20 orang $(33.3 \%)$ pada posisi berdiri (kasir) dan 6 orang $(13.1 \%)$ pada posisi berjalan (pramuniaga). Keluhan muskuloskeletal berupa bengkak terbanyak yaitu posisi mengangkat (Staf Area) 2 orang (1.2\%), 1 orang $(0.6 \%)$ pada posisi berjalan (pramuniaga) dan pada posisi berdiri (kasir) tidak dijumpai keluhan muskuloskeletal.
\end{abstract}

Kata Kunci : Ergonomi, Keluhan Muskuloskeletal, Posisi Kerja

\begin{abstract}
Ergonomics is the application of biological sciences about humans together with engineering and technological sciences to achieve adjustment. Musculoskeletal complaints are complaints of pain, pain, aches and more in the muscular (musculoskeletal) system such as tendons, blood vessels, joints, bones, nerves and others caused by work activities. A survey conducted by Simon Fraser University and the United Food and Commercial Workers indicates that $30 \%$ of unskilled workers suffer from MSD. The purpose of this study was to determine the relationship of various work positions with musculoseceletal complaints to employees of the Medan Johor Diamond supermarket. The benefits of this study are expected to be disseminated in the mass media about the relationship between work positions and musculoskeletal complaints so that they can be useful for other employees. The design of this study was a cross sectional approach to analytic research with a sample size of 60 people. This research was conducted from April to May 2018 and the data collection tool used was by using a questionnaire sheet. The results of this study indicate that musculoskeletal complaints are in the form of the most pain, namely in the lifting position (Area Staff) 31 people (50.6\%), where 20 people $(33.3 \%)$ in the standing position (cashier) and 6 people $(13.1 \%)$ in the walking position ) Musculoskeletal complaints in the form of the most swollen, namely lifting position (Area Staff) 2 people (1.2\%), 1 person $(0.6 \%)$ in a walking position (clerk) and in a standing position (cashier) musculoskeletal complaints were not found.
\end{abstract}

Keywords: Ergonomics, Musculoskeletal Complaints, Work Position 


\section{PENDAHULUAN}

$\begin{array}{ccc}\text { Pada } & \text { umumnya } & \text { kesehatan tenaga } \\ \text { pekerja } & \text { sangat } & \text { mempengaruhi }\end{array}$ perkembangan ekonomi dan pembangunan nasional termasuk dalam hal teknologi. Namun di lain pihak penggunaan teknologi maju cenderung untuk menimbulkan risiko bahaya kecelakaan dan penyakit akibat kerja yang lebih besar, baik di tempat kerja maupun di masyarakat pada umumnya. Ada beberapa faktor yang dapat menyebabkan terjadinya penyakit akibat kerja, namun dalam penelitian ini hanya akan dibahas mengenai faktor fisiologi atau ergonomi. Ergonomi yang merupakan pendekatan multi dan interdisiplin yang berupaya menserasikan alat, cara dan lingkungan kerja terhadap kemampuan dan kebolehan dan batasan tenaga kerja sehingga tercipta kondisi kerja yang sehat, selamat, aman, nyaman, dan efisien. Keluhan MSD yang sering timbul pada pekerja industri adalah nyeri punggung, nyeri leher, nyeri pada pergelangan tangan, siku dan kaki. Rumusan masalah dalam penelitian ini adalah adakah hubungan posisi kerja dengan keluhan muskuloskeletal pada karyawan-karyawati swalayan diamond Medan Johor. Dalam penelitian ini bertujuan untuk mengetahui hubungan posisi kerja dengan muskuloskeletal, penelitian diharapkan bermanfaat bagi karyawan-karyawati dan perusahaan terkait.

\section{TINJAUAN PUSTAKA}

Kata ergonomi berasal dari bahasa Yunani ergon (kerja) dan nomos (peraturan, hukum). Jadi, ergonomi merupakan penerapan ilmu-ilmu biologis tentang manusia bersama-sama dengan ilmu-ilmu teknik dan teknologi untuk mencapai penyesuaian satu sama lain secara optimal dari manusia terhadap pekerjaannya (Suma'mur, 1995). Adapun misi tujuan dari ergonomi yaitu:

1. Penyesuaian antara peralatan kerja dengan kondisi tenaga kerja yang menggunakan. Kondisi tenaga kerja ini bukan aspek fisiknya saja, tetapi juga kemampuan intelektual dan berpikirnya.

2. Apabila peralatan kerja dan tenaga kerja sudah cocok, maka kelelahan dapat dicegah dan hasilnya lebih efisien (Suma'mur, 1995).

Beberapa prinsip ergonomi di bawah ini antara lain dapat digunakan sebagai pegangan dalam program kesehatan kerja (Anonim).

a. Sikap tubuh dalam melakukan pekerjaan sangat dipengaruhi oleh bentuk, susunan, ukuran dan penempatan mesinmesin, penempatan alat-alat penunjuk serta cara-cara melayani mesin.

b. Untuk normalisasi ukuran mesin atau peralatan kerja harus diambil ukuran terbesar sebagai dasar serta diatur dengan suatu cara.

c. Ukuran-ukuran antopometri yang dapat dijadikan dasar untuk penempatan alatalat kerja seperti sikap berdiri atau duduk.

d. Pada pekerjaan tangan yang dilakukan berdiri, tinggi kerja sebaiknya $5-10 \mathrm{~cm}$ di bawah tinggi siku.

e. Dari segi otot, sikap duduk yang paling baik adalah sedikit membungkuk, sedang dari sudut tulang, dianjurkan duduk tegak agar punggung tidak bungkuk dan otot perut tidak lemas.

f. Terdapat tempat duduk yang baik.

g. Arah penglihatan ini sesuai dengan sikap kepala yang istirahat.

h. Ruang gerak lengan ditentukan oleh punggung lengan seluruhnya dan lengan bawah.

i. Kemampuan seseorang bekerja adalah 8-10 jam per hari. Lebih dari itu efisiensi dan efektivitas kerja menurun.

\section{Sistem Muskuloskeletal}

Seperti kita ketahui tubuh manusia tediri dari berbagai sistem, diantaranya sistem pencernaan, sistem otot (muscle), sistem pengindra (sensory) sistem kerangka (skeleton), sistem saraf (nervous) dan lainlain. Karena manusia merupakan subsistem dari sebuah sistem kerja, dan ergonomi bermaksud untuk membuat sistem kerja itu selamat, sehat, aman dan nyaman.

Beberapa pekerjaan mempunyai resiko ganguan muskuloskeletal atau Musculoskeltal Disorder (MSD). Ada beberapa faktor yang dapat menyebabkan MSD, namun faktor utamanya berupa tenaga yang dipaksakan (force), posisi yang 
tidak sesuai (awkward postures) dan pengulangan pekerjaan (repetition) (Fitrihana, 2009).

\section{METODE PENELITIAN}

Jenis penelitian yang digunakan adalah penelitian analitik dengan pendekatan secara cross sectional yaitu variabel bebas dan variabel terikat diobservasi hanya sekali pada saat yang sama.

Penelitian ini dilakukan di Swalayan Diamond Jalan Karya Wisata, Pangkalan Masyur Kec. Medan Johor dan dilakukan pada bulan Mei 2018.

Populasi adalah sekelompok subyek dengan karakteristik tertentu. Populasi pada penelitian ini adalah seluruh karyawan/i yang bekerja di Swalayan Diamond Medan Johor berjumlah 60 orang.

Sampel penelitian adalah sebagian dari populasi yang diteliti dan dianggap mewakili seluruh populasi.

Cara pemilihan sampel dalam penelitian ini dilakukan dengan cara total sampling. Cara pemilihan sampel yang diteliti diharapkan dapat memenuhi perhitungan jumlah yang mempunyai 60 sampel.

Teknik pengambilan sampel adalah menggunakan total sampling dengan cara menjadikan seluruh populasi sebagai sampel penelitian.

Pada penelitian ini, instrumen yang digunakan adalah kuesioner yang sudah dilakukan uji validitas dan uji reliabilitas. Kuesioner diadopsi dari metode "Nordic Body Map" (NBM). Metode ini merupakan adalah metode yang digunakan untuk menilai tingkat keparahan atas terjadinya gangguan atau cedera pada otot-otot skeletal. Penilaian dengan menggunakan 2 jawaban "YA" (ada keluhan muskuloskeletal) dan "TIDAK" (tidak ada keluhan muskuloskeletal). Setiap pertanyaan atau satu jawaban mengandung point satu.artinya jika ditotalkan terdapat 27 point. Adapunketentuan point sebagai berikut:

1. 1-5: keluhan tidak mengganggu aktivitas

2. 5-27: keluhan menganggu aktivitas.
Teknik pengumpulan data dilakukan melalui data primer. Data primer adalah data yang diambil langsung dari responden melalui pembagian kuesioner yang selanjutnya diisi oleh responden.

Data yang terkumpul diubah secara manual dan selanjutnya disajikan dalam bentuk tabel distribusi frekuensi dengan tahapan:

a. Editing, dilakukan dengan memeriksa data yang telah dikumpulkan apabila terdapat kesalahan atau data yang belum lengkap maka diperbaiki atau diulang.

b. Coding, data yang telah terkumpul dan telah di korelasi ketepatan dan kelengkapannya diberi kode-kode dalam bentuk angka.

c. Tabulating, data yang telah diperiksa keseragamannya dikelompokkan kedalam satu tabel sederhana.

d. Entry, data dimasukkan kedalam program komputer.

e. Cleaning, pemeriksaan semua data yang telah dimasukkan kedalam program komputer guna menghindari terjadinya kesalahan dalam pemasukan data.

f. Scoring atau nilai, dalam pemberian skor digunakan bebrapa tipe penilaian berdasarkan data yang didapat.

g. Saving, menyimpan data yang sudah di cek untuk kemudian dianalisa.

Data yang telah terkumpul kemudian dianalisa dengan;

a. Analisis Univariat : dilakukan untuk mendeskripsikan karakteristik dari variabel independen dan variabel dependen.

b. Analisis Bivariat : dilakukan untuk mencari adanya hubungan antara dua variabel (variabel dependen dan variabel independen) menggunakan uji Chisquare dengan $\alpha=0.05$.

\section{HASIL DAN PEMBAHASAN \\ Analisis Univariat}

1. Didapati bahwa umumnya jenis kelamin responden pada bagian kasir adalah perempuan sebanyak 18 orang $(90,0 \%)$, pada bagian pramuniaga lebih banyak laki-laki yaitu 6 orang $(100 \%)$ dan bagian staf area laki-laki sebanyak 33 orang $(97,1 \%)$. 
2. Didapati bahwa umumnya kelompok usia responden pada bagian kasir adalah 21 - 25 tahun sebanyak 14 orang $(70,0 \%)$ dan paling sedikit usia 31-35 tahun yaitu 1 orang $(5,0 \%)$. Pada bagian pramuniaga lebih banyak berusia 21-35 tahun yaitu 5 orang $(83,3 \%)$ dan pada bagian staf area lebih banyak berumur 21-25 tahun dan 26-30 tahun masing masing 13 orang $(38,2 \%)$, sedangkan paling sedikit adalah kelompok usia 3135 tahun sebanyak 1 orang $(2,9 \%)$.

\begin{tabular}{|c|c|c|c|c|c|c|}
\hline \multirow{2}{*}{$\begin{array}{l}\text { Variabel } \\
\text { Bebas }\end{array}$} & \multicolumn{4}{|c|}{ Variabel Terikat } & \multirow{3}{*}{$\begin{array}{l}\mathrm{T} \\
\text { ot } \\
\text { al }\end{array}$} & \multirow{3}{*}{$\begin{array}{l}p \text { - } \\
\text { Val } \\
\text { ue }\end{array}$} \\
\hline & \multicolumn{2}{|c|}{ Nyeri } & \multicolumn{2}{|c|}{$\begin{array}{l}\text { Bengka } \\
\mathrm{k}\end{array}$} & & \\
\hline Posisi Kerja & $\mathrm{N}$ & $\%$ & $\mathrm{~N}$ & $\%$ & & \\
\hline Berjalan & 20 & $\begin{array}{l}33 . \\
3\end{array}$ & 0 & 0 & 20 & \\
\hline Berdiri & 6 & $\begin{array}{l}13 . \\
1\end{array}$ & 1 & 0.6 & 7 & $\begin{array}{l}0.0 \\
05\end{array}$ \\
\hline Mengangkat & 31 & $\begin{array}{l}50 . \\
6\end{array}$ & 2 & 1.2 & 33 & $\begin{array}{l}(>0 \\
.05)\end{array}$ \\
\hline Total & 57 & $\begin{array}{l}10 \\
0.0\end{array}$ & 3 & $\begin{array}{l}10 \\
0.0\end{array}$ & 60 & \\
\hline
\end{tabular}

3. Didapati bahwa umumnya masa kerja responden pada bagian kasir adalah 1-4 tahun sebanyak 10 orang $(50,0 \%)$, pada bagian pramuniaga lebih banyak telah bekerja selama 5-8 tahun yaitu 4 orang $(66,7 \%)$ dan bagian staf area telah bekejra 5-8 tahun sebanyak 18 orang $(52,9 \%)$.

4. Berdasarkan Distribusi Demografi menurut Posisi Pekerjaan didapati kasir adalah sebanyak 20 orang (33.3\%), sebagai pramuniaga sebanyak 6 orang $(14.3 \%)$ dan sebagai staf area sebanyak 34 orang $(52.4 \%)$.

5. Distribusi Demografi menurut Status Perkawinan didapati bahwa sebagian besar karyawan/i belum menikah yaitu sebanyak 48 orang $(80 \%)$ dan sebanyak 12 orang $(20 \%)$ sudah menikah.

6. Didapati bahwa umumnya keluhan gangguan pada leher terjadi pada semua bagian. Kejadian gangguan pada leher pada bagian kasir sebanyak 14 orang $(70,0 \%)$, pada bagian pramuniaga yaitu 1 orang $(16,7 \%)$ dan bagian staf area sebanyak 13 orang $(38,2 \%)$.

7. Didapati bahwa umumnya keluhan nyeri bahu terjadi pada bagian kasir dan staf administrasi. Kejadian nyeri bahu pada bagian kasir sebanyak 10 orang (50,0\%), pada bagian pramuniaga tidak ada $(0 \%)$ dan bagian staf area sebanyak 6 orang $(17,6 \%)$.

8. didapati bahwa umumnya keluhan nyeri pungung terjadi pada semua bagian. Kejadian nyeri punggung pada bagian kasir sebanyak 12 orang $(70,6 \%)$, pada bagian pramuniaga yaitu 6 orang $(100 \%)$ dan bagian staf area sebanyak 21 orang $(80,8 \%)$.

9. Didapati bahwa umumnya keluhan nyeri siku terjadi pada bagian kasir dan staf area. Responden pada bagian kasir yang mengalami nyeri siku sebanyak 2 orang $(10,0 \%)$, sedangkan pada bagian staf area sebanyak 4 orang $(11,8 \%)$.

10. Didapati bahwa keluhan nyeri/bengkak pada kaki hanya terjadi pada bagian staf area sebanyak 3 orang $(8,8 \%)$, sedangkan bagian lain tidak mengalami nyeri kaki.

\section{Analisis Bivariat}

*Chi Square Test $\alpha=0,05$

Tabel diatas menunjukkan bahwa keluhan muskuloskeletal berupa nyeri terbanyak yaitu pada posisi mengangkat (Staf Area) 31 orang $(50.6 \%)$, dimana 20 orang $(33.3 \%)$ pada posisi berdiri (kasir) dan 6 orang $(13.1 \%)$ pada posisi berjalan (pramuniaga). Keluhan muskuloskeletal berupa bengkak terbanyak yaitu posisi mengangkat (Staf Area) 2 orang (1.2\%), 1 orang $(0.6 \%)$ pada posisi berjalan (pramuniaga) dan pada posisi berdiri (kasir) tidak dijumpai keluhan muskuloskeletal.

Pembahasan

Hasil uji statistk chi-square menunjukkan $p$-value yang berarti adanya hubungan bermakna statistik antara posisi kerja dengan keluhan muskuloskeletal pada karyawan-karyawati Swalayan Diamond Medan Johor Periode Mei 2018, hasil uji statistik juga menunjukkan coefficient correlation $r=0.388$ yang berarti kekuatan hubungan sedang.

Hasil dari penelitian ini juga sesuai dengan penelitian yang telah dilakukan oleh Dewi Sri A Simatupang tahun 2017 terhadap pekerja di bagian Produksi PT. Perkebunan Nusantara IV Unit Teh Bah Butong didapatkan hasil sebesar 26 
responden mengalami keluhan pada punggung, 27 responden mengalami keluhan pada bahu, siku dan tangan dan 8 responden mengalami keluhan pada kaki.

Hasil ini sesuai dari teori menurut Fitrihana (2009) dimana keluhan muskuloskeletal yang sering timbul pada pekerja industri adalah nyeri punggung, nyeri leher, nyeri pada pergelanga tangan, siku dan kaki. Adapun faktor yang dapat meningkatkan keluhan muskuloskeletal yaitu postur yang tidak alami, tenaga berlebihan, pengulangan berkali-kali dan lamanya waktu kerja.

\section{Kesimpulan \& Saran \\ Kesimpulan}

Berdasarkan hasil penelitian dan pembahasan yang telah dijabarkan pada bab sebelumnya, maka kesimpulan yang dapat ditarik dalam penelitian ini adalah sebagai berikut:

1. Terdapat hubungan antara posisi kerja berdiri (kasir) dengan keluhan muskuloskeletal berupa nyeri yaitu terdapat 20 orang $(33.3 \%)$

2. Terdapat hubungan posisi kerja berjalan (praminuaga) dengan keluhan muskuloskeletal berupa nyeri dang bengkak yaitu sebanyak 7 orang $(13.1 \%)$.

3. Terdapat hubungan posisi kerja mengangkat (staf area) dengan keluhan muskuloskeletal berupa nyeri sebanyak 31 orang $(50,1 \%)$ dan pada bengkak sebanyak 2 orang (1.2\%).

4. Hasil uji statistik menggunakan chisquare menunjukkan p-value $<0.005$ yang berarti adanya hubungan yang bermakna antara posisi kerja dengan keluhan muskuloskeletal, hasil uji statistik juga menunjukkan coefficient correlation $r=0.388$ yang berarti kekuatan hubungan sedang.

\section{Saran}

Berdasarkan hasil penelitian dan pembahasan yang telah dijabarkan pada bab sebelumnya, maka saran yang dapat diberikan dalam penelitian ini adalah sebagai berikut:

1. Kepada pimpinan perusahaan agar memberikan perhatian pada pekerja pria dan wanita, sebab mereka merupakan ujung tombak perusahaan yang dapat mempengaruhi tingkat produktivitas perusahaan, dimana mereka juga secara tidak langsung memberikan konstribusi bagi kemajuan industri daerah.

2. Kepada pemerhati masalah ketenagakerjaan seperti pemerintah setempat dan instansi terkait agar dapat kiranya melakukan penyuluhanpenyuluhan tentang kesehatan kerja bagi pekerja, misalnya dengan memberikan penyuluhan-penyuluhan tentang pentingnya istirahat yang cukup, konsumsi kalsium yang cukup dan segera berobat ke puskesmas atau balai kesehatan lainnya untuk mengatasi keluhan muskuloskeletal yang ada agar tetap bekerja dengan baik.

3. Bagi peneliti selanjutnya untuk meneliti dengan lokasi dan sampel yang lebih besar terkait tentang keluhan muskuloskeletal yang ditimbulkan akibat pekerjaan.

\section{DAFTAR PUSTAKA}

Anonim. Musculoskeletal Disorders Prevention Series. Occupational Health and Safety Council of Ontario (OHSCO). Prevention Guidline.

Anonim. $2005 . \quad$ Work-related Musculoskeletal Disorders. Available from URL: http://www.ccohs.com

Anonim. 2008. Serasikan Alat, Cara dan Lingkungan Kerja. Available from http://www.unmul.ac.id

Anonim. 2009. Prinsip Dasar Kesehatan Kerja. Available from URL: http://www.depkes.go.id

Anonim. 2006. Focus on Wellness: Musculoskeletal Disorders. Available from: URL: http://www.atu.com

Chairuddin, R. 2003. Pengantar ilmu Bedah Ortopedi. Bintang Lamumpatue, Makassar.

Hendrawansilondae. 2005. Hubungan Beban Kerja dan Ergonomis. Available from: URL: http://www.hendra'ssite.com. 
Joseph, L. 2002. Current Occupational \& Environmental Medicine. Mc Graw Hill, San Fransisco.

Noor Fitrihana. 2009. Upaya Mengurangi Resiko Muskuloskeletal. Available from URL: http://.Lusisusanti.com

Notoatmojo, S. 2011. Ilmu Kesehatan Masyarakat.Prinsip-Prinsip Dasar. Penerbit Rineka Cipta, Jakarta.

Notoatmodjo. S. 2012. Metodologi Penelitian Kesehatan. Rineka Cipta, Jakarta.

Putu, S., I., D. 2006. Hambatan Dalam Penerapan K3 dan Ergonomi di Perusahaan. Bagian Fisiologi Fakultas Kedokteran Program Pascasarjana Universitas Udayana.
Sulistomo, A. 2002. Diagnosis Penyakit Akibat Kerja dan Sistem Rujukan.

Suma'mur. 1995. Faal Kerja dan Ergonomi. In: Higene Perusahaan dan Kesehatan Kerja. PT. Gunung Agung, Jakarta.

Susyanti, D, Parlagutan, M.T, Pratama, M.Y. 2018. Pengalaman Perawat Melakukan Latihan Aktifitas Fisik pada Pasien Congestive Hearth Failure. Jurnal Riset Hesti Medan. Tanggal akses 5 Desember 2018.

Suyatno, S. 1985. Meningkatkan Produktivitas Dengan Ergonomi. PT. Pustaka Binaman Pressindo, Jakarta. 